\title{
Symmetric Multi-Level Boost Inverter with Single DC Source Using Reduced Number of Switches
}

\author{
Marikkannu MARIMUTHU*, Subramanian VIJAYALAKSHMI
}

\begin{abstract}
In this paper a novel multilevel boost DC to DC converter with $\mathrm{H}$-Bridge inverter circuit for single DC source is proposed. The proposed scheme has two stages: the first one is a multilevel boost converter which gives a multilevel dc output for a single dc source and the second level is a H-Bridge converter which converts multilevel DC to multilevel AC at required frequency. This DC-DC converter not only reduces the DC source but also reduces the switches, diodes and capacitors. This leads to decrease of the amount and the inverter space installation in order to increase the required output voltage by increasing the number of capacitors and diodes in the DC to DC converter Comparison between the number of power switches for the suggested topology and other topologies in the recent literature is presented. Simulation results are conveyed through MatLAB/Simulink domain and the working of the suggested converter is realized.
\end{abstract}

Keywords: level circuit; multi-level boost converter (MBC); multi-level inverter (MLI); pulse width modulation (PWM); total harmonic distortion (THD)

\section{INTRODUCTION}

In order to achieve high boost ratios and excellent efficiency, there are several implemented boost topologies with transformer-less converter. In the conventional boost converter, the capacitor current is discontinuous resulting in larger capacitor size and EMI issues [1-5]. The MBC is the mixture of traditional boost DC-DC converter and the switched capacitor which works to provide different output voltages and a self-sustained voltage using one inductor, one switch, $2 M-1(M-$ number of level) capacitors and $2 M-1$ diodes for $\mathrm{M}^{*} \mathrm{MBC}$. It is a PWM based boost converter, where there are different required voltage levels with unidirectional current flow, and self-adjusting various level converters [6-11]. The main advantages of this converter are: it allows high switching frequency, a high gain beyond extreme duty cycle, continuous input current, and excludes transformer. Without modifying the main circuit, more levels of the converter should be achieved by adding diodes and capacitors. In order to achieve reduced switching losses, improved high voltage operation capability, less Electro Magnetic Interference (EMI), and high voltage gain, multilevel inverters are preferred.

To fulfill the demand of power rating and improved power quality with the reduced harmonic distortion, multilevel inverter is better than conventional inverter. Because the gate pulse used in the switches of MLI is high switching frequency PWM is recommended. Due to the easiness of the control and modularity the MLI is highly preferable to conventional inverter.

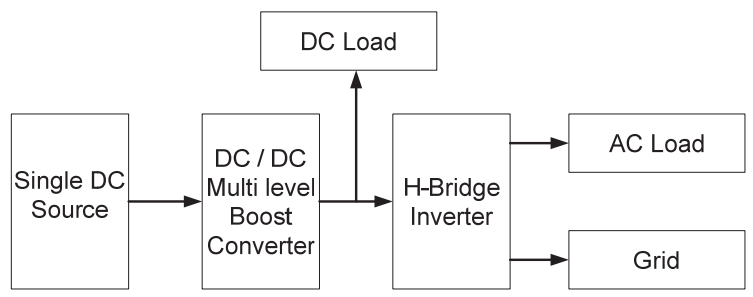

Figure 1a Proposed MLI block diagram

The AC power supply with high power quality and less THD is the primary requirement for the significance of High power. To meet this requirement multilevel inverters are normally used for their sinusoidal like output. In general, the renewable energy sources are DC. It is very hard to get a pure sinusoidal AC output with the use of filters. It may increase overall cost of the system. Hence multilevel inverters are used in such applications. Multilevel inverters are classified into two major categories with single source and multiple sources. HBridge topology is used in multiple source inverters and the single source inverters use large capacitor banks. Fig. 1b shows the proposed MLI topology with Multi level Boost converter topology.

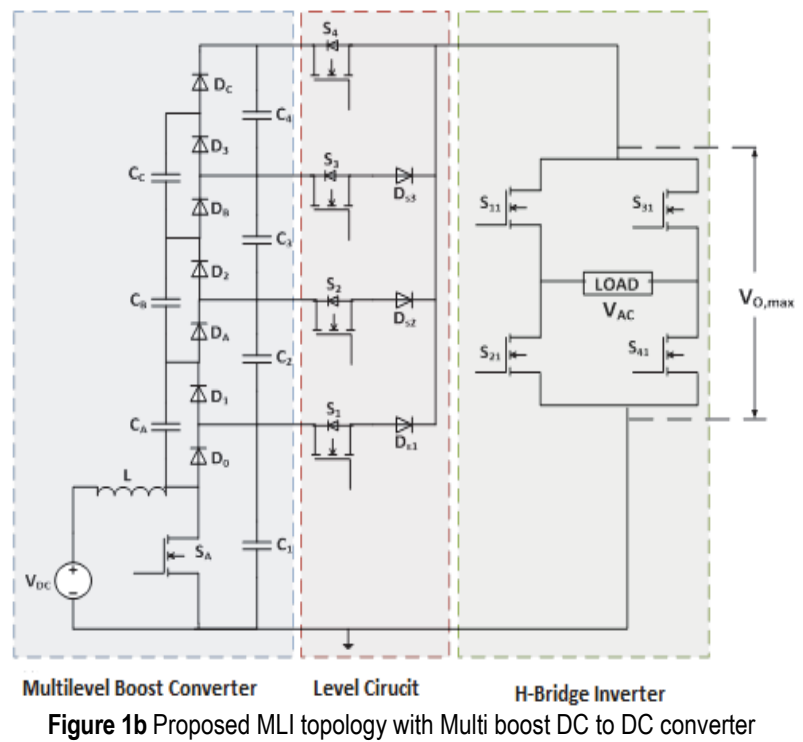

The minimum power renewable energy sources have no significance in high power applications, the dc boost converters are used to interface low power sources [20]. The proposed topology can be built for both low and high power application. This circuit consists of a single source multi-level boost converter whose output is the source of $\mathrm{H}$ Bridge inverter. M-level inverter output can be obtained through this topology. The M-level stepped AC output voltage waveform can be obtained using one DC source, minimum number of switches, diodes and capacitors.

Applications of the extended MLI circuit are listed below: computer, telecom power supplies in remote areas supplied from solar panels, electric vehicles [22], uninterrupted power supplies [4] and renewable energy microgrid $[21,23]$. 


\section{PROPOSED TOPOLOGY}

Fig. $1 \mathrm{~b}$ depicts the symmetric 9-level inverter. It consists of three units for DC-AC conversion: 1. the multilevel DC to DC Boost converter, 2. the AC output level changing circuit and 3. the conventional H-Bridge inverter. The Multilevel DC-DC Boost converter is the extension of traditional boost converter.

\section{MULTILEVEL BOOST CONVERTER}

The Boost converter with multilevels consists of a conventional boost converter combined with the voltage multiplier stages as shown in Fig. 2. This MBC contains a switch, inductor, $2 M-1$ Capacitors and $2 M-1$ diodes to attain the $M$ times of the output voltage of the traditional boost converter. In the proposed topology four levels output is designed. For 4 levels DC output 7 diodes and 7 capacitors are used. In Fig. 1, first part shows the four level boost converters. One important feature of the multilevel $\mathrm{dc}-\mathrm{dc}$ boost converter is that the level numbers can be raised by adding only diodes and capacitors and need not modify the prime circuit $[12,13]$.

In First part of Fig. 1, $V_{\mathrm{dc}}, L, S 1$ constitutes a conventional boost converter. The remaining components in the circuit provide a multiplier output that is VC times $M$, where $2 M+1$ is the converter number of levels considering the significance of the zero level. The voltage output and the current through the Inductor of the traditional boost converter is

$$
\frac{V_{\mathrm{C}}}{V_{\mathrm{dc}}}=\frac{1}{1-D}
$$

$$
I_{\mathrm{L}}=\frac{V_{\mathrm{O}}}{(1-D) R}
$$

where $V_{\mathrm{C}}, V_{\mathrm{dc}}, D, I_{\mathrm{L}}$, and $R$ are the output voltage, input source voltage, duty ratio, inductor current, and load resistance respectively.

The new voltage gain can be expressed by Voltage gain

$$
N=M \times \frac{1}{1-D}=M \times K
$$

where $M$ is the Level of Boost Converter

$D$ is the Duty cycle $=\frac{T_{\mathrm{ON}}}{T_{\mathrm{ON}}+T_{\mathrm{OFF}}}$

$T_{\mathrm{ON}}-$ Switch ON time

$T_{\mathrm{OFF}}-$ Switch OFF time

The inductance $L_{\text {crit }}$ of the converter is resolved by the duty cycle $D$, the switching frequency and the Load resistance $R$

$$
L_{\text {crit }}=\frac{D \times(1-D) \times R}{2 \times f}
$$

The value of the capacitor is designed based on

$$
C=\frac{D}{R \times f \times V_{\mathrm{r}}}
$$

where $V_{\mathrm{r}}$ is the output voltage ripple factor

$$
V_{\mathrm{r}}=\frac{\Delta V_{\text {out }}}{V_{\text {out }}}
$$

The voltage stress across switch and diode will be calculated as

$$
V_{\mathrm{str}}=\frac{V_{\mathrm{dc}}}{1-D}
$$

The potential of the $k^{\text {th }}$ level stage across the capacitor

$$
k V_{\mathrm{c}}=\frac{V_{\mathrm{dc}}}{1-D}-n V_{\mathrm{D}}
$$

where $M$ is the total number of diodes encountered till the $n^{\text {th }}$ stage. Multilevel Boost converter has two modes of operation, described below.

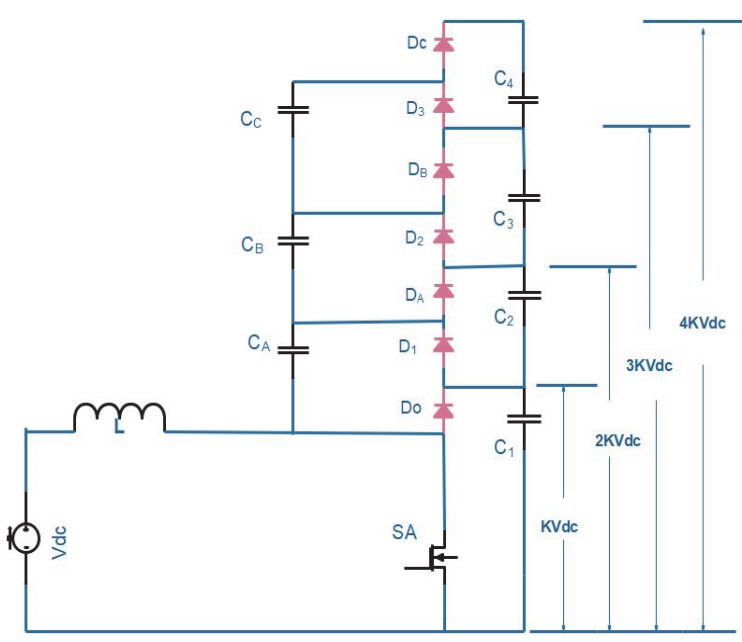

Figure 2 Multi level Boost Converter

During the switch $S_{\mathrm{A}}$ in ON state, the source voltage $V_{\mathrm{dc}}$ is charged by the inductor. The capacitor $C_{\mathrm{A}}$ voltage is less than the voltage of $C_{1}$, then the $C_{1}$ voltage is clasped across $C_{\mathrm{A}}$ through the diode $D_{1}$. In a synchronic way if $C_{\mathrm{A}}$ $+C_{\mathrm{B}}+C_{\mathrm{C}}$ voltage is less than $C_{1}+C_{2}+C_{3}$ then $C_{3}, C_{2}, C_{1}$ clasp the voltage across $C_{\mathrm{A}}, C_{\mathrm{B}}, C_{\mathrm{C}}$.

When Switch $S_{\mathrm{A}}$ is OFF condition, $D_{0}$ is closed and all diodes are made to conduct because of inductor current. Finally, $C_{4}, C_{3}, C_{2}, C_{1}$ is clasped by $C_{\mathrm{C}}, C_{\mathrm{B}}, C_{\mathrm{A}}$, input voltage and inductor voltage.

\section{LEVEL CIRCUIT}

The function of the level circuit in the prescribed topology is to produce the stepped level input to the HBridge inverter. The switch $S_{1}$ is ON then the voltage at the capacitor $C_{1}\left(k V_{\mathrm{dc}}\right)$ is the input of $\mathrm{H}$-Bridge inverter through $S_{1}$ and $D_{1}$. When $S_{2}$ is $\mathrm{ON}$, then the sum of the voltage at $C_{1}$ 
and $C_{2}\left(2 k V_{\mathrm{dc}}\right)$ is the inverter input. Similarly when $S_{3}, S_{4}$ is $\mathrm{ON}$ then the inverter input is $3 k V_{\mathrm{dc}}$ and $4 k V_{\mathrm{dc}}$ respectively. The operation of the Level circuit is depicted in Tab. 1.

Table 1 Level circuit operation
\begin{tabular}{|c|c|c|c|c|}
\hline$S_{1}$ & $S_{2}$ & $S_{3}$ & $S_{4}$ & Output from level circuit \\
\hline 1 & 0 & 0 & 0 & $+k V_{\mathrm{dc}}$ \\
\hline 0 & 1 & 0 & 0 & $+2 k V_{\mathrm{dc}}$ \\
\hline 0 & 0 & 1 & 0 & $+3 k V_{\mathrm{dc}}$ \\
\hline 0 & 0 & 0 & 1 & $+4 k V_{\mathrm{dc}}$ \\
\hline
\end{tabular}

\section{MLI WITH SINGLE H-BRIDGE}

Fig. 3 is the H-Bridge inverter derived from the model graphical representation of such a circuit.

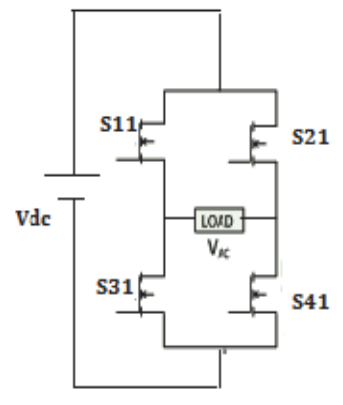

Figure $3 \mathrm{H}$-Bridge inverter

A H-Bridge is constructed by four power switches namely MOSFET, IGBT, or BJT. Whenever the switches $S_{11}$ and $S_{41}$ are turned $\mathrm{ON}$ a positive voltage will be applied to the load and the switches $S_{21}$ and $S_{31}$ are closing; then the reverse voltage is applied to the load. Tab. 2 and Fig. 4 represent the level selection, inverter operation and its corresponding output.

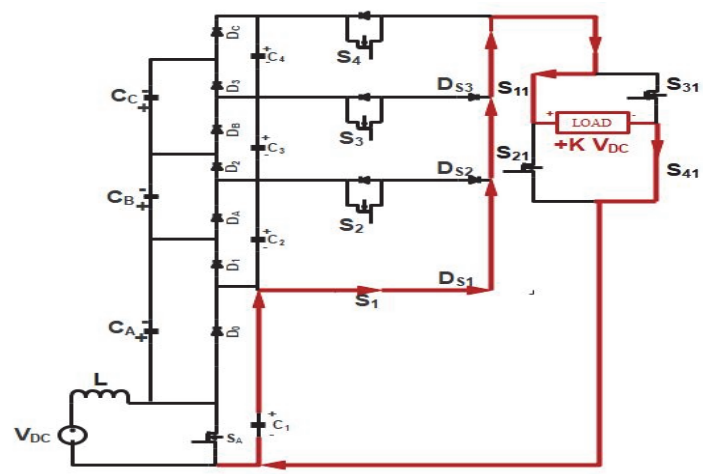

(a) Multi level inverter output is $k V_{d c}$

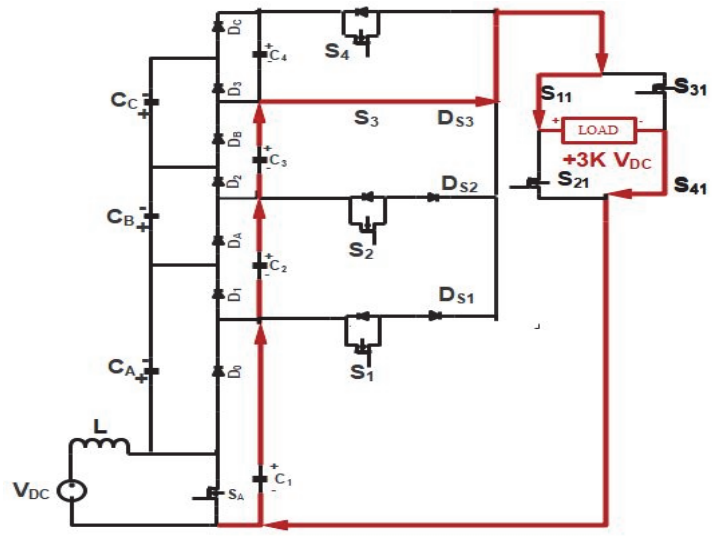

(c) Multi level inverter output is $3 k V_{d c}$
In relation to the input voltage level of inverter, the output voltage level of the inverter is found. The number of output voltage levels of the inverter is taken as $M$, and $\mathrm{n}$ is the multi boost converter output voltage level number.

The number of switches $=5+n$

Number of diodes $=\frac{3 M-7}{2}$

Number of capacitors $=M-2$

Inverter level $M=2 n+1$

The output voltage across the multi-level boost converter is

$V_{0 \mathrm{DC}}=\sum_{i=1}^{\frac{M-1}{2}} V_{i}$

where $V_{i}$ is the individual capacitor voltage

$=\frac{V_{\text {in }}}{1-D} \times M$

$D$ is the switching ratio of Boost converter

$V_{0, \max }=\left\{\begin{array}{l}+\sum_{i=1}^{\frac{N-1}{2}} V_{i}, S_{11}=S_{41}=\mathrm{ON} \\ -\sum_{i=1}^{\frac{N-1}{2}} V_{i}, S_{21}=S_{31}=\mathrm{ON}\end{array}\right.$ (b) Multi level inverter output is $2 k V_{d c}$

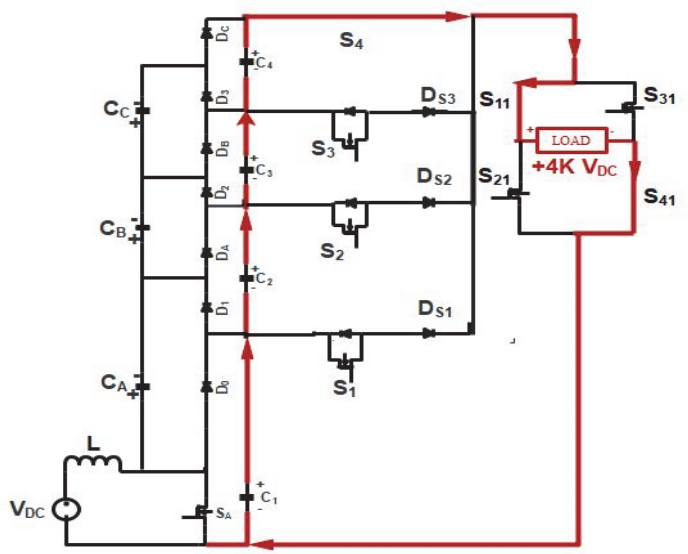

(d) Multi level inverter output is $4 k V_{d c}$

Figure 4 Multi level inverter operation 


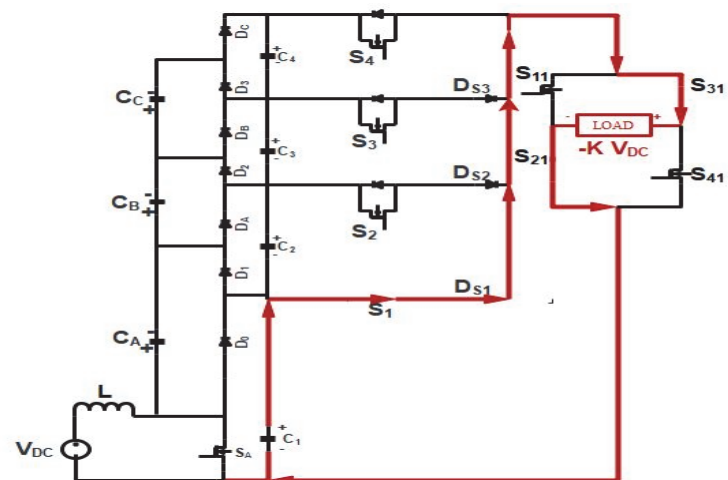

(e) Multi level inverter output is $-k V_{d c}$

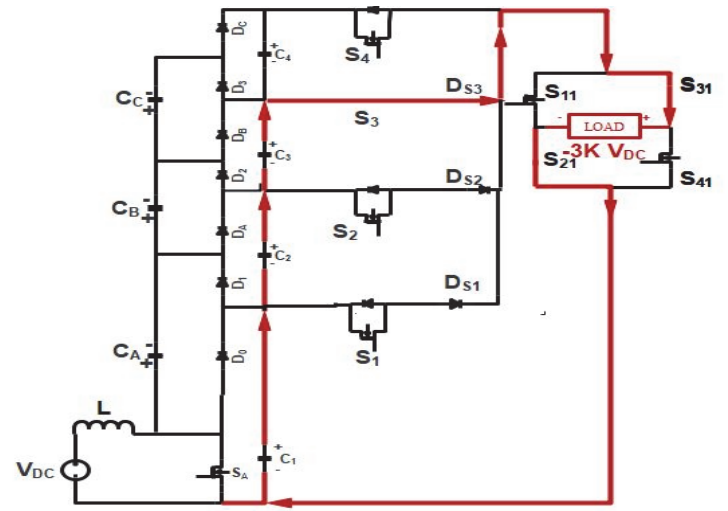

(g) Multi level inverter output is $-3 k V_{d c}$

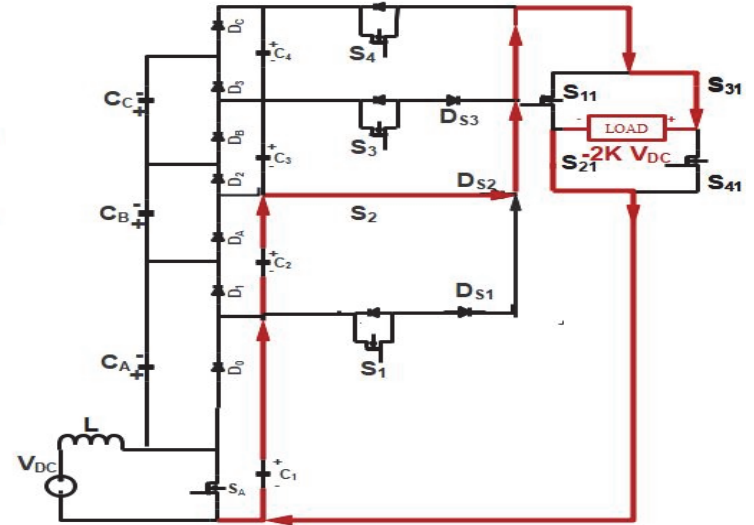

(f) Multi level inverter output is $-2 k V_{d c}$

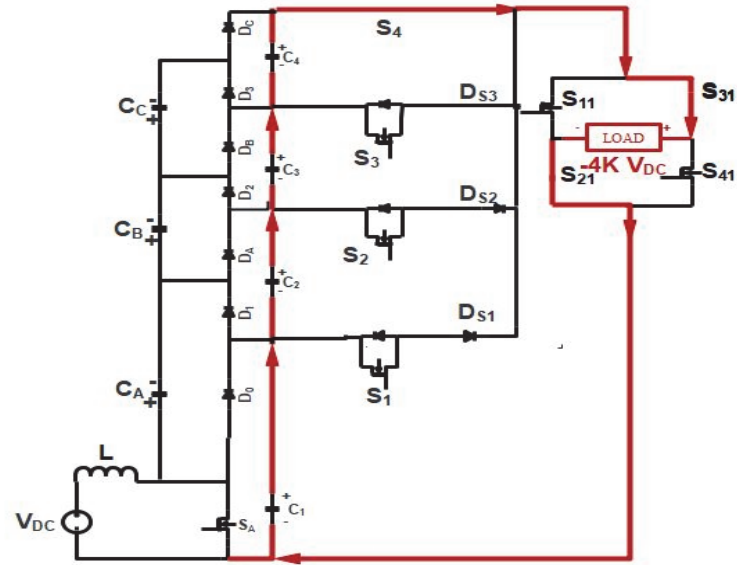

(h) Multi level inverter output is $-4 k V_{d c}$

Figure 4 Multi level inverter operation (continuation)

Fig. 4a shows the voltage at $C_{1}\left(k V_{\mathrm{dc}}\right)$ applied to the inverter load via the switch $S_{1}, D_{\mathrm{S} 1}, S_{11}$ and $S_{41}$, Similarly the sum of voltage at $C_{1}$ and $C_{2}$ is applied to the load via the switch $S_{2}, D_{\mathrm{S} 2}, S_{11}$ and $S_{41}$ is depicted in Fig. $4 \mathrm{~b}$. Similarly $3 k V_{\mathrm{dc}}, 4 k V_{\mathrm{dc}}, k V_{\mathrm{dc}},-2 k V_{\mathrm{dc}},-3 k V_{\mathrm{dc}},-4 k V_{\mathrm{dc}}$ is illustrated in Figa. $4 \mathrm{c}, 4 \mathrm{~d}, 4 \mathrm{e}, 4 \mathrm{f}, 4 \mathrm{~g}$ and $4 \mathrm{~h}$ respectively. The operation of multilevel inverter is also explained through Tab. 2.

\begin{tabular}{|c|c|c|c|c|c|c|}
\hline & \multirow{2}{*}{ Levels } & \multicolumn{4}{|c|}{ Switching sequence } & \multirow{2}{*}{$\begin{array}{l}\text { Voltage } \\
\text { Levels }\end{array}$} \\
\hline & & $S 1$ & $S 2$ & $S 3$ & $S 4$ & \\
\hline \multirow{9}{*}{$\begin{array}{c}\text { Positive } \\
\text { Half cycle } \\
S 11, S 41 \\
\text { ON }\end{array}$} & 0 & OFF & OFF & OFF & OFF & 0 \\
\hline & 1 & $\mathrm{ON}$ & OFF & OFF & OFF & $+k V_{\mathrm{dc}}$ \\
\hline & 2 & OFF & $\mathrm{ON}$ & OFF & OFF & $+2 k V_{\mathrm{dc}}$ \\
\hline & 3 & OFF & OFF & $\mathrm{ON}$ & OFF & $+3 k V_{\mathrm{dc}}$ \\
\hline & 4 & OFF & OFF & OFF & $\mathrm{ON}$ & $+4 k V_{\mathrm{dc}}$ \\
\hline & 3 & OFF & OFF & $\mathrm{ON}$ & OFF & $+3 k V_{\mathrm{dc}}$ \\
\hline & 2 & OFF & $\mathrm{ON}$ & OFF & OFF & $+2 k V_{\mathrm{dc}}$ \\
\hline & 1 & $\mathrm{ON}$ & OFF & OFF & OFF & $+k V_{\mathrm{dc}}$ \\
\hline & 0 & OFF & OFF & OFF & OFF & 0 \\
\hline \multirow{8}{*}{$\begin{array}{c}\text { Negative } \\
\text { Half cycle } \\
S 21, S 31 \\
\text { ON }\end{array}$} & 1 & $\mathrm{ON}$ & OFF & OFF & OFF & $-k V_{\mathrm{dc}}$ \\
\hline & 2 & OFF & $\mathrm{ON}$ & OFF & OFF & $-2 k V_{\mathrm{dc}}$ \\
\hline & 3 & OFF & OFF & $\mathrm{ON}$ & OFF & $-3 k V_{\mathrm{dc}}$ \\
\hline & 4 & OFF & OFF & OFF & $\mathrm{ON}$ & $-4 k V_{\mathrm{dc}}$ \\
\hline & 3 & OFF & OFF & $\mathrm{ON}$ & OFF & $-3 k V_{\mathrm{dc}}$ \\
\hline & 2 & OFF & $\mathrm{ON}$ & OFF & OFF & $-2 k V_{\mathrm{dC}}$ \\
\hline & 1 & $\mathrm{ON}$ & OFF & OFF & OFF & $-k V_{\mathrm{dc}}$ \\
\hline & 0 & OFF & OFF & OFF & OFF & 0 \\
\hline
\end{tabular}

\section{SIMULATION RESULTS}

Fig. 5 depicts the simulated topology for H-Bridge inverter with $\mathrm{MBC}$ using MatLAB/Simulink. The gate pulse whose switching frequency is $10 \mathrm{kHz}$ and $50 \%$ duty cycle of PWM pulse is given to the multilevel boost converter switch. The selection of level circuit switches is made through MatLAB program. In the H-bridge inverter, for the first $10 \mathrm{mS}$ gate pulse with the frequency of $100 \mathrm{~Hz}$ is given to the positive output pair $\left(S_{11}\right.$ and $\left.S_{41}\right)$ the next 10 $\mathrm{mS}$ gate pulse is given to negative output pair $\left(S_{21}\right.$ and $\left.S_{31}\right)$. The design parameters of the multilevel boost converter fed $\mathrm{H}$-Bridge inverter of the simulation circuit are shown in Tab. 2.

The DC voltage input of the MBC is $21 \mathrm{~V}$ and the capacitor voltage (output) $C 1$ is $46 \mathrm{~V}$, sum of $C 1$ and $C 2$ output is $86 \mathrm{~V}$. Simultaneously by the addition of $C 1, C 2$ and $C 3$, and $C 1, C 2, C 3$ and $C 4$ outputs are $126 \mathrm{~V}$ and 166 $\mathrm{V}$ respectively, illustrated in Fig. 5. Tab. 3 depicts the design parameters of Multilevel Boost converter fed HBridge inverter. By using the Eqs. (4) and (5), the inductor and capacitor values are calculated.

Table 3 Design parameters of multilevel boost converter fed $\mathrm{H}$-Bridge inverter

\begin{tabular}{|l|c|}
\hline \multicolumn{1}{|c|}{ Parameters } & Values \\
\hline Input voltage for DC-DC Converter & $21 \mathrm{~V}$ \\
\hline Output voltage for both DC-DC converter \& Inverter & $168 \mathrm{~V}$ \\
\hline Duty cycle & $50 \%$ \\
\hline Capacitor $C_{1}, C_{2}, C_{3}, C_{4}, C_{\mathrm{A}}, C_{\mathrm{B}}, C_{\mathrm{C}}$ & $89 \mu \mathrm{F}$ \\
\hline Inductor & $8 \mathrm{mH}$ \\
\hline Switching frequency of MBC & $10 \mathrm{kHz}$ \\
\hline Switching frequency of MLI & $50 \mathrm{~Hz}$ \\
\hline Load Resistance & $25 \Omega$ \\
\hline
\end{tabular}

The H-Bridge 9-level inverter output voltage $(0$, $40,80,120,160,-40,-80,-120,-160)$ with the total time period of $20 \mathrm{mS}$ is depicted in Fig. 6. Depending upon the load value the output current will be varied. The output current inverter waveform is also illustrated in Fig. 6. 


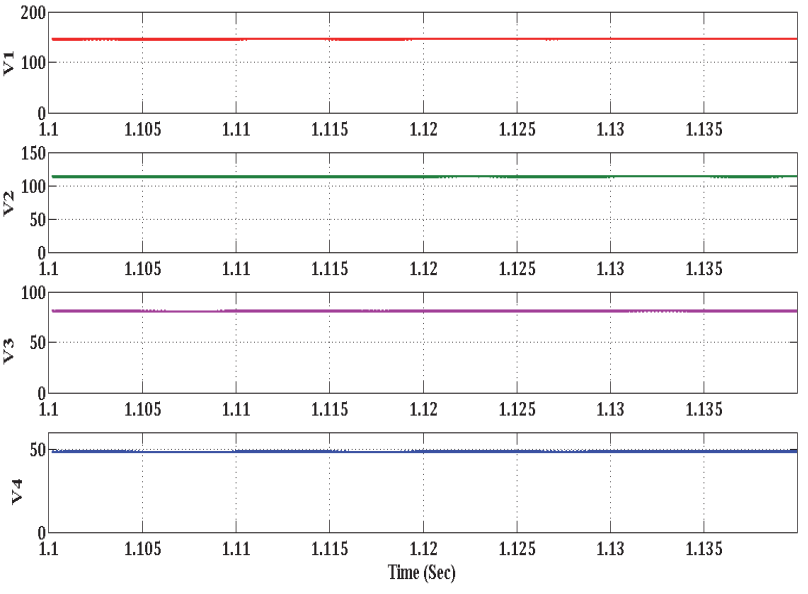

Figure 5 Capacitor output voltages at Multi level boost converter

\section{RESULTS AND DISCUSSION}

Key traits of the proposed topology with its correlatives are analyzed with Multilevel Inverter as NPCMLI, FCMLI, CHBI, Symmetric MLC (SMLC) [16], SCQNLI [18], A Cascaded MLI based on Switched Capacitor [19], Self-balanced step-up MLI [14], and A Quasi Resonant Switched Capacitor MLI (QRSCMLI) with self-voltage stabilizing [15] is depicted in Tab. 4. A comparative analysis of some of the key traits of the recommended topology with its correlative is presented in Tab. 4. The evaluation is made in terms of number of switches $\left(N_{\text {swi }}\right)$, number of gate drives $\left(N_{\text {dri }}\right)$, sources $\left(N_{\text {sou }}\right)$, and the diodes $\left(N_{\text {dio }}\right)$ for nine level multi level inverter.
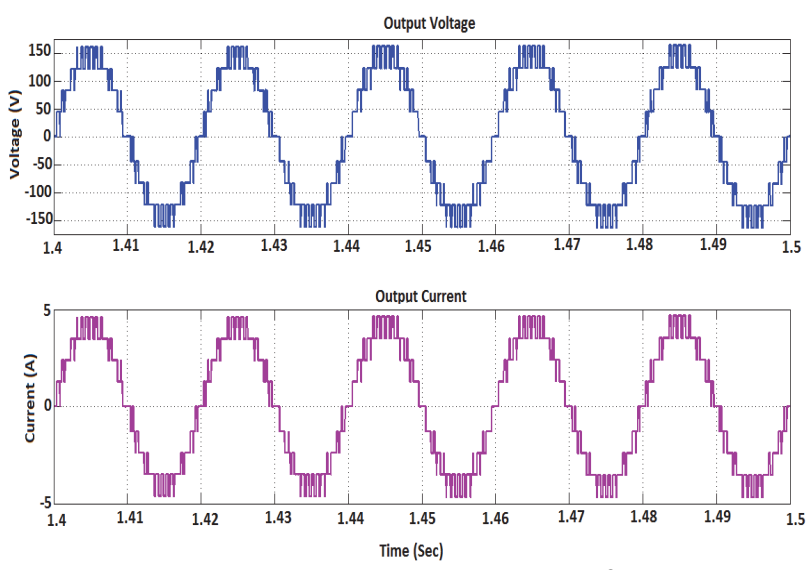

Figure $6 \mathrm{H}$-Bridge inverter output voltage and Current

In terms of reliability, the second critical component is that of the capacitors, and it is essential to hold on its count lesser.

Table 4 Comparison of the recommended MLI with the preexisting and present recommended topologies Component count

\begin{tabular}{|l|c|c|c|c|c|}
\hline Reference Name or No. & $N_{\text {swi }}$ & $N_{\text {dri }}$ & $N_{\text {dio }}$ & $N_{\text {cap }}$ & $N_{\text {sou }}$ \\
\hline NPC MLI & 16 & 16 & 56 & 8 & 1 \\
\hline FC MLI & 16 & 16 & -- & 36 & 1 \\
\hline CHB & 16 & 16 & -- & -- & 4 \\
\hline$[16]$ & 10 & 10 & -- & 4 & 2 \\
\hline$[18]$ & 12 & 12 & 0 & 2 & 1 \\
\hline$[19]$ & 12 & 12 & 2 & 2 & 2 \\
\hline$[14]$ & 19 & 19 & 3 & 3 & 1 \\
\hline$[15]$ & 10 & 10 & 4 & 4 & 1 \\
\hline Proposed & 9 & 9 & 10 & 7 & 1 \\
\hline
\end{tabular}

It is visible from Tab. 4 that one of the MLIs, the recommend circuit needs a lesser count of switches, sources and driver circuit. Further generalized circuits have a higher number of switches, and also have too many of either capacitors, or diodes or sources, which increases not only the cost but losses also, which substantially decreases the efficiency of the circuit. The remaining circuits [14-19] have more switches than the proposed one.

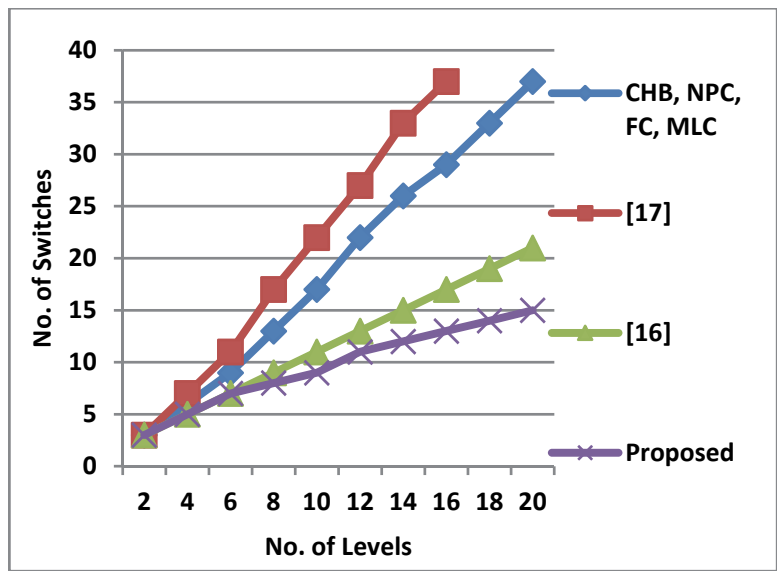

Figure 7 Number of levels $V_{s}$ amount of switches for MLI

The number of levels $V_{\mathrm{S}}$ number of switches is given in Fig. 7. From the graph one can understand that the $\mathrm{CHB}$, NPC, FC and [17] need higher number of switches. It is clear that recommended topology needs lesser amount of switches than the other topologies.

\section{HARDWARE RESULTS}

The prototype model for Multilevel DC-DC converter fed H-Bridge inverter is depicted in Fig. 7. The components used in the prototype model are shown in Tab. 5.

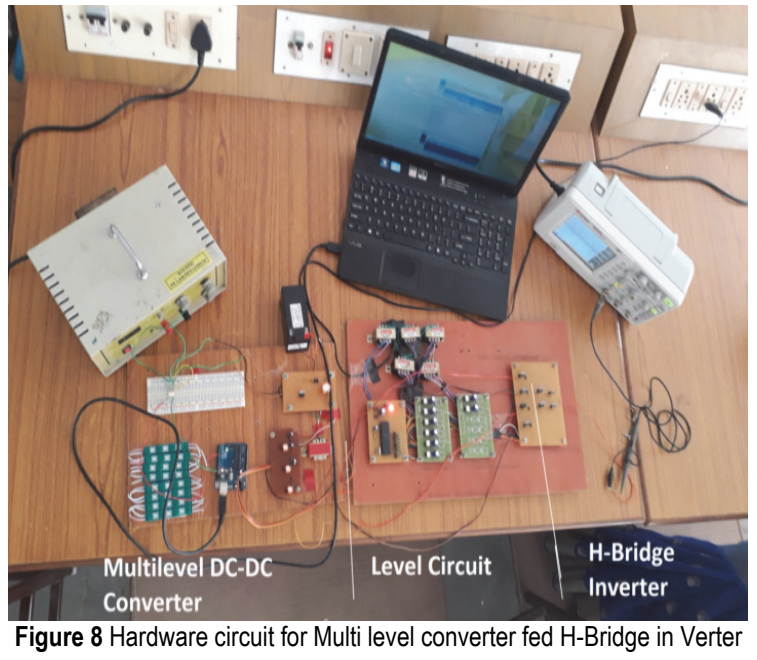

The input voltage given to the MBC DC/DC boost converter is $2.8 \mathrm{~V}$, and the pulse with $50 \%$ duty ratio of the boost converter is furnished in Fig. 9. Four different output voltage levels can be attained in the boost converter. At level $1(C 1)$ and level $2(C 1+C 2)$, the obtained output voltage is $5.6 \mathrm{~V}, 11.2 \mathrm{~V}$ respectively, illustrated in Fig. 10 . The level 3 voltage is $(C 1+C 2+C 3)$ and the voltage at level $4(C 1+C 2+C 3+C 4)$ is $16.8 \mathrm{~V}$ and $22.4 \mathrm{~V}$ 
respectively depicted in Fig. 11. The gate pulse with the time period of $10 \mathrm{mS}$ given to the couple of the switch in the H-Bridge Inverter is furnished in Fig. 12. AC output obtained from the MLI is shown in Fig. 13.

Table 5 Experimental values for the proposed circuit

\begin{tabular}{|l|c|}
\hline \multicolumn{1}{|c|}{ Description } & Experimental values \\
\hline MOSFET & IRF 840 \\
\hline Diode & $2 \mathrm{~N} 4007$ \\
\hline Duty cycle & $50 \%$ \\
\hline Capacitor $C_{1}, C_{2}, C_{3}, C_{4}, C_{\mathrm{A}}, C_{\mathrm{B}}, C_{\mathrm{C}}$ & $70 \mu \mathrm{F}$ \\
\hline Inductor & $7 \mathrm{mH}$ \\
\hline Switching frequency of DC-DC converter & $10 \mathrm{kHz}$ \\
\hline Switching frequency of Inverter & $50 \mathrm{~Hz}$ \\
\hline Load Resistance & $100 \mathrm{Ohm}$ \\
\hline Input Voltage $\left(V_{\mathrm{dc}}\right)$ & $2.8 \mathrm{~V}$ \\
\hline Multi level DC Output Voltage $\left(V_{\mathrm{o}}\right)$ & $5.6 \mathrm{~V}, 11.2 \mathrm{~V}, 16.8 \mathrm{~V}$, \\
\hline Input current $\left(I_{\text {in }}\right)$ & $1.9 \mathrm{~A}$ \\
\hline Load current $\left(I_{\mathrm{o}}\right)$ & $0.9 \mathrm{~A}$ \\
\hline $\begin{array}{l}\text { Pulse generated for Multi level DC } \\
\text { converter by Arduino controller (SMDR3) }\end{array}$ & $5 \mathrm{~V}, 10 \mathrm{kHz}$ \\
\hline $\begin{array}{l}\text { Pulse generated for H-Bridge Inveter by } \\
\text { Mircocontroller (ATMEL 89S51) }\end{array}$ & $5 \mathrm{~V}, 50 \mathrm{~Hz}$ \\
\hline
\end{tabular}

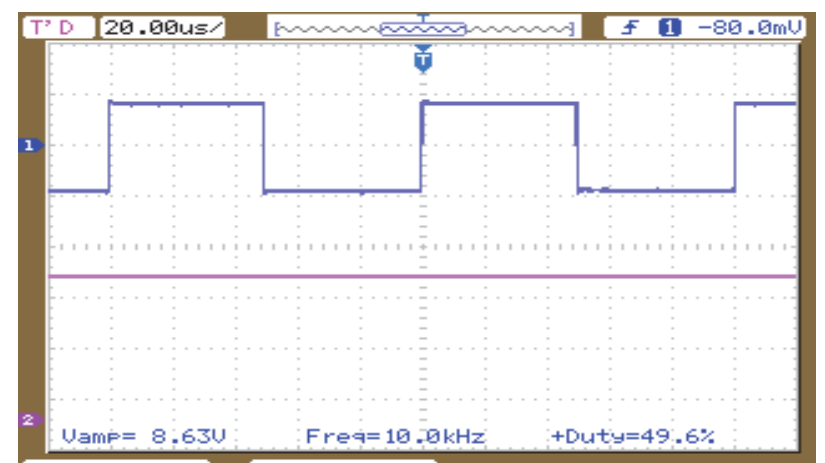

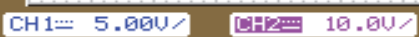

Figure 9 Multilevel boost converter input voltage (2.8 V) and the gate pulse (10 $\mathrm{kHz}$ ) for main switch

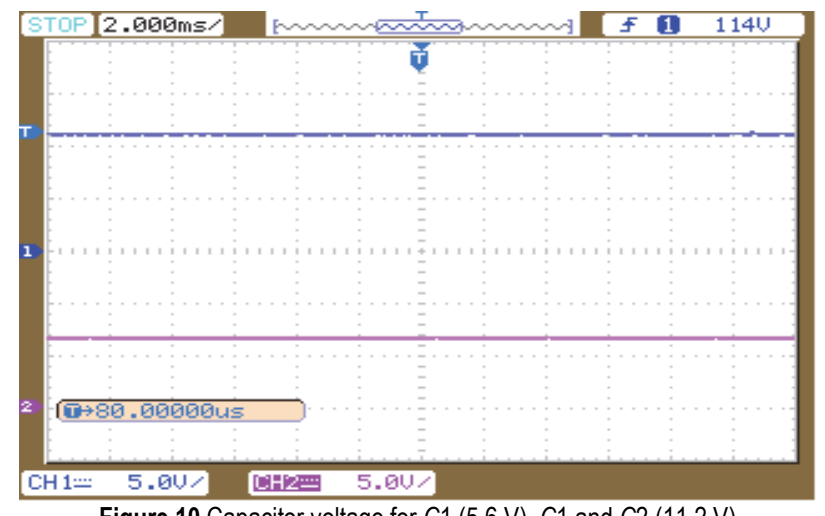

Figure 10 Capacitor voltage for C1 (5.6 V), C1 and C2 (11.2 V)

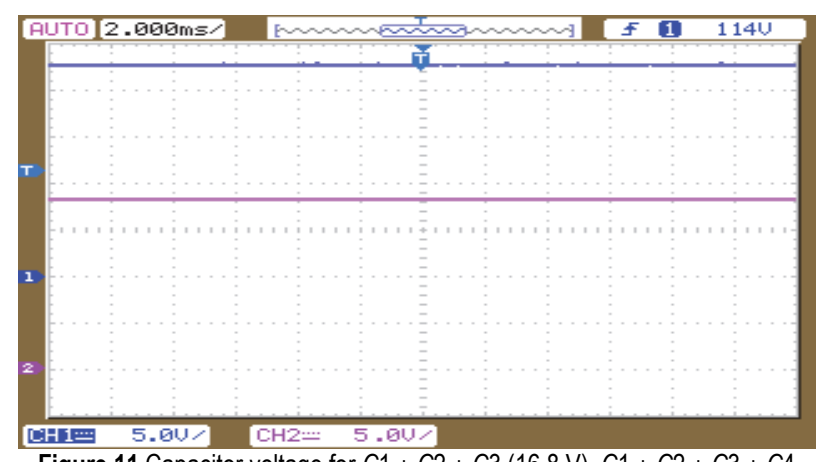

Figure 11 Capacitor voltage for $C 1+C 2+C 3(16.8 \mathrm{~V}), C 1+C 2+C 3+C 4$

$(22.4 \mathrm{~V})$

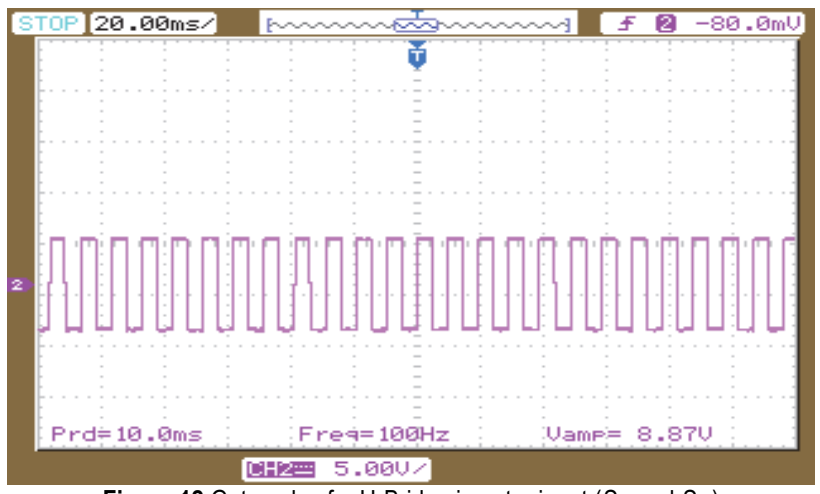

Figure 12 Gate pulse for $\mathrm{H}$-Bridge inverter input $\left(S_{11}\right.$ and $\left.S_{31}\right)$

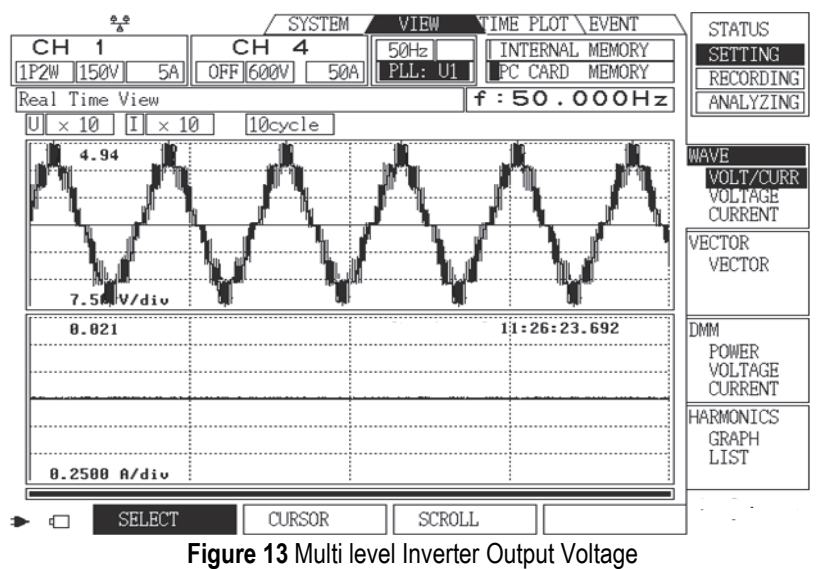

\section{CONCLUSION}

The proposed modern multilevel inverter has required isolated voltage source (DC) and minimum quantity of switches. An input voltage from the DC source has been boosted up at a different level. It needs only a conventional $\mathrm{H}$-Bridge Inverter for obtaining any number of required levels of the inverter. The proposed topology extends up to the required quantity of levels and could be raised by raising the number of diodes and capacitors only. It decreases the amount of diodes, switches, cost, dimension of the system and the amplitude of the total blocked reverse voltage in verification with the conventional and similar circuits. At the end, the capability and working of $M$ level MLI circuit has been proved with various simulations and practical outcomes.

\section{REFERENCES}

[1] Alishah, R. S., Hosseini, Babaei, E., \& Sabahi, M. (2016). A New General Multilevel Converter Topology Based on Cascaded Connection of Sub multi-level Units with Reduced Switching Components, DC Sources, and Blocked Voltage by Switches. IEEE Trans. Ind. Electron., 63(11), 7157-7164. https://doi.org/10.1109/TIE.2016.2592460

[2] Gupta, K. K., Alekh, R., Pallavee, B., Lalit, K. S., \& Shailendra, J. (2016). Multilevel inverter topologies with reduced device count: a review. IEEE Transactions on Power Electronics, 31(1), 135-151. https://doi.org/10.1109/TPEL.2015.2405012

[3] Malinowski, M., Gopakumar, K., Rodriguez, J., \& Perez, M. A. (2010). A Survey on Cascaded Multilevel Inverters. IEEE Trans. Ind. Electron, 57(7), 2197-2206. https://doi.org/10.1109/TIE.2009.2030767

[4] Uthirasamy, R., Uthandipalayam, S. R., \& Venkatachalam, K. C. (2015). Structure of boost DC-link cascaded multilevel 
inverter for uninterrupted power supply applications. IET Power Electronics, 8(11), 2085-2096. https://doi.org/10.1049/iet-pel.2014.0746

[5] Vijayaakshmi, S. \& Sree Renga Raja, T. (2014). Time domain based digital PWM controller for DC-DC converter. Automatika, 55(4), 434-445. https://doi.org/10.7305/automatika.2014.12.552

[6] Shalchi Alishah, R., Nazarpour, D., Hosseini, S. H., \&. Sabahi, M. (2015). Reduction of Power Electronic Elements in Multilevel Converters Using a New Cascade Structure. IEEE Trans. Ind. Electron, 62(1), 256-269. https://doi.org/10.1109/TIE.2014.2331012

[7] Alishah, R. S., Hosseini, S. H., Babaei, E., \& Sabahi, M. (2017). Optimal Design of New Cascaded Switch-Ladder Multilevel Inverter Structure. IEEE Trans. Ind. Electron, 64(3), 2072-2080. https://doi.org/10.1109/TIE.2016.2627019

[8] Ebrahimi, J., Babaei, E., \& Gharehpetian, G. B. (2012). A New Multi-level Converter Topology with Reduced Number of Power Electronic Components. IEEE Trans. Ind. Electron 59(2), 655-667. https://doi.org/10.1109/TIE.2011.2151813

[9] Ebrahimi, J., Babaei, E., \& Gharehpetian, G. B. (2011). A New Topology of Cascaded Multilevel Converters with Reduced Number of Components for High-Voltage Applications. IEEE Trans. Power Electron, 26(11), 31093118. https://doi.org/10.1109/TPEL.2011.2148177

[10] Babaei, E., Laali, S., \& Bahravar, S. (2015). A New Cascaded Multi level Inverter Topology with Reduced Number of Components and Charge Balance Control Methods Capabilities. Electric Power Components and Systems, 43(19), 2116-2130. https://doi.org/10.1080/15325008.2015.1077485

[11] Babaei, E., Laali, S., \& Alilu, S. (2014). Cascaded Multilevel Inverter with Series Connection of Novel H-Bridge Basic Units. IEEE Trans. Ind. Electron., 61(12), 6664-6671. https://doi.org/10.1109/TIE.2014.2316264

[12] Mokhberdoran, A. \& Ajami, A. (2014). Symmetric and Asymmetric Design and Implementation of New Cascaded Multilevel Inverter Topology. IEEE Trans. Power Electron., 29(12), 6712-6724. https://doi.org/10.1109/TPEL.2014.2302873

[13] Taghvaie, A., Adabi, J., \& Rezanejad, M. (2017). A Multilevel Inverter Structure Based on a Combination of Switched-Capacitors and DC Sources. IEEE Trans. Ind. Informatics., 13(5), 2162-2171. https://doi.org/10.1109/TII.2017.2710265

[14] Taghvae, A., Adabi, J., \& Renanejad, M. (2018). A selfbalanced step-up multi-level inverter based on switched capacitor structure. IEEE Trans. Power Electron, 33(1), 199209. https://doi.org/10.1109/TPEL.2017.2669377

[15] Zeng, J., Liu, N., Wu, J., \& Goe, H. (2017). A quasi-resonant switched capacitor multi-level inverter with self-voltage balancing. IEEE Trans. Ind. Informatics, 13(5), 2669-2679. https://doi.org/10.1109/TII.2017.2672733

[16] Jagobar, S. M. Ali, R. A., \& Vijayakumar, K. (2018). A new symmetric multilevel converter Topology with reduced voltage on switches and DC source. IEEE.

[17] Taghvae, A., Adabi, J., \& Renanejad, M. (2017). A multilevel Inverter structure based on a combination of switched capacitor and DC sources. IEEE Tras. Ind. Informatics, 13(5), 2162-2171. https://doi.org/10.1109/TII.2017.2710265

[18] Sandeep, N., Jagabarsahik, M. A., Udaykumar, R., \& Krishnaswamy, V. (2018). Switched - Capacitor based quadruple boost nine level Inverter. IEEE Transactions on Power Electronics. https://doi.org/10.1109/TPEL.2019.2898225

[19] Junfeng, L. \& Cheng. K. W. E. (2018). A Cascaded multilevel Inverter based on Switched 67 Capacitor for high frequency AC power Distribution System. IEEE transaction on Power Electronics, 29(8).

[20] Sivakumar, S., Jagabar Sathik, M., Manoj, P. S., \& Sundararajan, G. (2016). An assessment on performance of DC-DC converters for renewable energy applications.
Renewable and Sustainable Energy Reviews, 58, 1475-1485. https://doi.org/10.1016/j.rser.2015.12.057

[21] Chakraborty, S. \& Simoes, M. G. (2009). Experimental evaluation of active filtering in a single-phase highfrequency AC microgrid. IEEE Trans. Energy Convers. 24(3), 673-682. https://doi.org/10.1109/TEC.2009.2015998

[22] Bose, B. K., Kin, M. H., \& Kankam, M. D. (1996). High frequency $\mathrm{AC}$ vs. DC distribution system for next generation hybrid electric vehicle. Proc. IEEE Int. Conf. Ind. Electron., Control, Instrum. (IECON), 2, 706-712.

[23] Zeng, J., Wu, L. J., \& Guo. H. (2017). A quasi-resonant switched-capacitor multilevel inverter with self-voltage balancing for single-phase high frequency ac microgrids. IEEE Trans. Ind. Inform., 13(5), 2669-2679. https://doi.org/10.1109/TII.2017.2672733

\section{Contact information:}

\section{Marikkannu MARIMUTHU}

(Corresponding author)

Saranathan College of Engineering,

Trichy, Tamilnadu, India - 620012

E-mail: marimuthueeephd@gmail.com

Subramanian VIJAYALAKSHMI

Saranathan College of Engineering,

Trichy, Tamilnadu, India - 620012

E-mail: bksvijigmail.com 